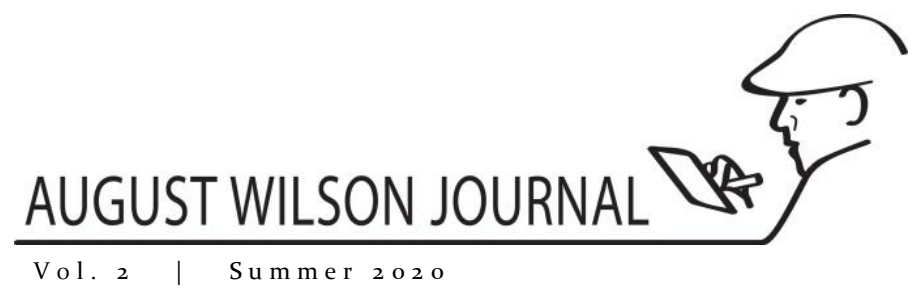

\title{
Stage Review of Fences
}

\author{
Chattanooga Theatre Centre \\ Chattanooga, Tennessee \\ Saturday, February 16, 2019 \\ By E. Andrew Lee \\ Professor of English, Lee University
}

\begin{abstract}
Staging the play in the round emphasized the home as a crucible of volatile reactions among disparate and dynamic personalities.
\end{abstract}

- Andrew Lee

\begin{abstract}
A stage review of Fences by August Wilson, staged by the Chattanooga Theatre Centre in Chattanooga, Tennessee from Friday, February 15 through Saturday, March 9, 2019.

Keywords

August Wilson, Fences, Chattanooga Theatre Centre, Troy Maxson, Rose Maxson, Ricardo C. Morris
\end{abstract}

The 1950 of of August Wilson's Fences can seem like a far-away world, but under the direction of Ricardo C. Morris at the Chattanooga Theatre Centre, the trials of the Maxson family seemed immediate, urgent, and inescapable. This production was staged "in the round" with audience members seated on three sides surrounding the yard and front porch of the Maxson home. The front rows of seats were only a few feet away from the actors, creating a powerful immediacy and intimacy that only the theatre can provide, an opportunity to eavesdrop on the private lives gathered in the Maxson yard, porch, and kitchen. Staging the play in the round emphasized the home as a crucible of volatile reactions among disparate and dynamic personalities. One section of spectators witnessed Lyons and Bono entering and exiting stage left, representing the societal threshold where the outside world collided with the Maxson family. The yard stage right, on the other

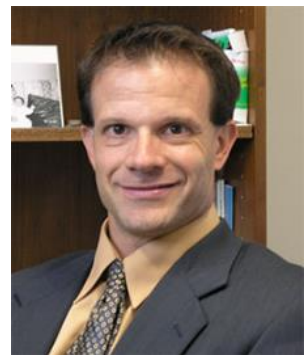

Andrew Lee hand, was a battleground for skirmishes between Troy and Cory, as well as the scene of confrontations between Rose and Troy.

The exterior of the Maxson home was meticulously realistic, with a wrap-around front porch offering a unique vantage point for the audience in the round, as well as a seethrough kitchen window allowing the audience to observe characters inside the house and engaging in telephone conversations. There were, however, two incongruities between Wilson's stage directions and this particular set design; these would be insignificant for audience members unfamiliar with the script, but these changes seemed puzzling and 
perhaps a bit conspicuous. One was the absence of the icebox on the front porch, perhaps a subtle metaphor for the Maxson family dynamics; the other discrepancy was an actual leather baseball tied to a rope hanging from a tree in the Maxson front yard. Wilson's script describes

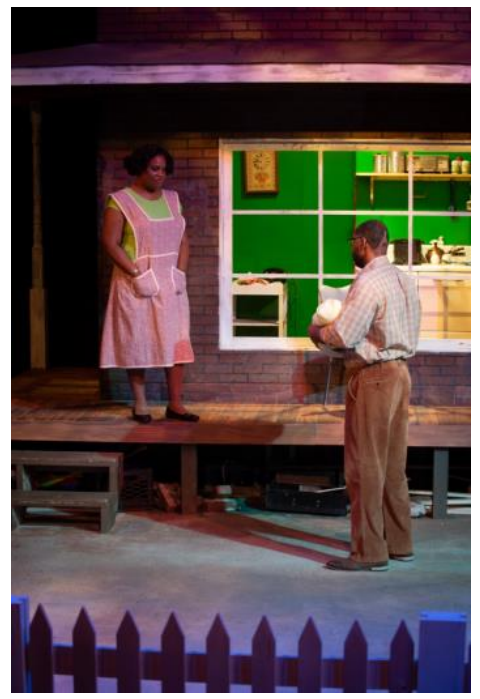
a clump of rags wound tightly into a ball rather than an actual baseball-suggesting not only Troy's ingenuity and determination to continue his batting practice even into his middle age, but also reminding us that Troy was cast off like rags by the major leagues and now is as tightly wound as the ball of rags itself.

When Mateen Muhammed El ambled onto the stage as Troy Maxson, bottle in hand and brimming with braggadocio, many were stunned into an awed silence. If Troy is a larger than life character (and he is), then Morris made an ingenious casting choice-Muhammed $\mathrm{El}$ is a formidable and daunting presence, well over six feet tall, built like an NFL tight end, with muscular forearms suggesting, appropriately, a pair of baseball bats ready for battle at any moment. Muhammed El's portrayal of Troy at times seemed reminiscent of Denzel Washington in the Oscar-nominated movie, from squinting in anger at his defiant son Cory, to his playfully assertive posturing when speaking to his wife Rose in front

E'Tienne F. Easley and Mateen of Jim Bono. Indeed, Muhammed El made Troy seem like three different men-amiable with Bono, aggressive with Cory, and usually frisky and affectionate with Rose.

Opposite Muhammed El, E'Tienne F. Easley was magnificent as the long-suffering yet resilient Rose Maxson. When tenderly teasing Troy about his exaggerated storytelling, or erupting into anguish at her husband's betrayals, Easley's Rose was pitch-perfect whether the moment called for affirmation or indignation. The intimate staging allowed the audience to see the sweat on Rose's brow during these pivotal moments. Easley seemed the most experienced and polished actor among a very strong cast. Carlos Davis as Troy's sounding board, Jim Bono, was perhaps the most genuinely likable character in the play-not only due to Wilson's sensitive and nuanced characterization, but also due to Davis's authenticity and infectious spirit of camaraderie. Davis's Bono was the friend who never faltered, a truth-teller, and Davis made him affable, thoughtful, and believable. Moreover, he elicited sympathy with Troy even at Troy's lowest moments, rather like a Greek chorus interpreting the action for the audience.

Jeffery Pinkerton as Troy's mentally disabled brother, Gabriel Maxson, faced perhaps the most difficult challengeto make Gabe memorable and prophetic without lapsing into

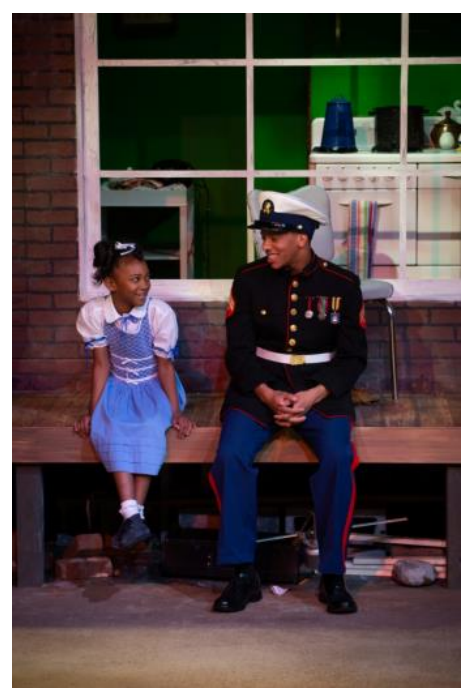

Nyla Jacks and Caleb Golson as Raynell and Cory lazy caricature which might evoke the audience's ridicule or contempt. Pinkerton's baldness and slight build paralleled Gabe's fragile mental state, and he excelled by remaining within himself and resisting any over the top antics. Gabriel's character evoked our admiration rather than our laughter, and gratitude for his optimism and loyalty rather than pity or shame for his tragic circumstances. William Elston made a stalwart turn as Troy's wayward son Lyons Maxson; an oversized hat hid his dreadlocks, perhaps belying Lyons' wariness about his father's disapproval, yet his steadfast belief in the redeeming power of music leaves us believing his future may be bright after all. The two youngest members of 
the cast were the most delightfully surprising-Caleb Golson as Cory and Nyla Jacks as Raynell. Golson, a Chattanooga native, was astonishing with his baby-faced yearning for Troy's approval, gradually evolving into equivocal defiance. The production program noted that Golson is renowned locally as "Caleb the Poet," and his performance as Cory was dramatically lyrical and moving - we wanted to see him emerge victoriously from these trials. Appearing in only the final scene of the play, Nyla Jacks's Raynell was the rainbow after the storm, pig-tailed and adorable, allowing us to breathe and to believe-her garden will grow; her life will be beautiful, and she will somehow atone for, as Wilson writes in the play's preface, "the sins of the fathers."

Director Ricardo Morris orchestrated the play's enigmatic final scene to make Troy's entrance into Heaven not only plausible but persuasive. Morris effectively utilized the close proximity of the round theatre by having Troy's silhouette appear in an upstairs bedroom window as Gabe performed a soft-shoe shuffle and the stage lights brightened, marking the moment of Troy's redemption. Though dead, Troy was still here, and the intimate staging emphasized his abiding presence.

\section{Work Cited}

Wilson, August. Fences. Theatre Communications Group. 2007.

\section{Author Bio}

Dr. Andrew Lee is Professor of English at Lee University in Cleveland, Tennessee.

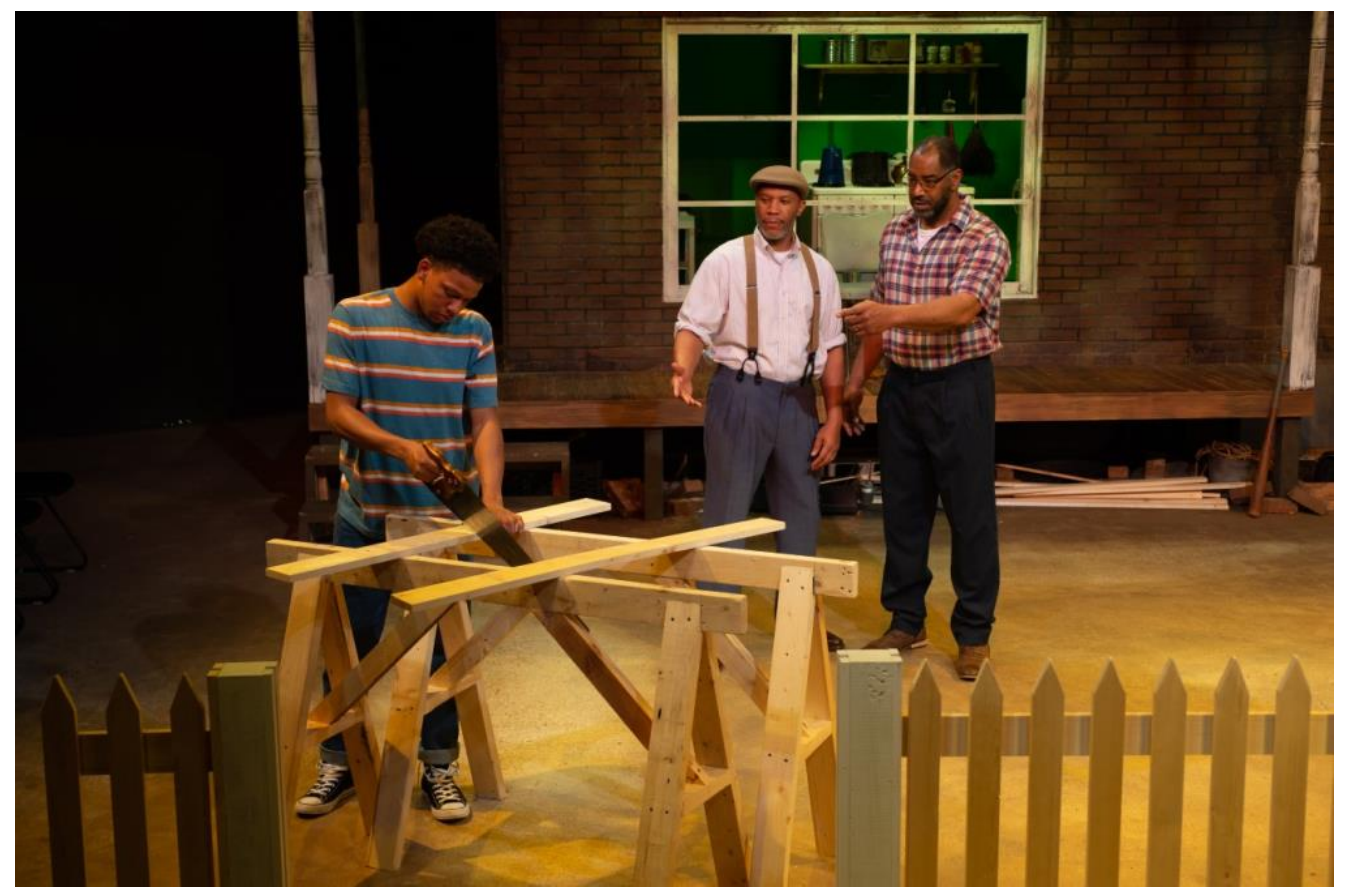




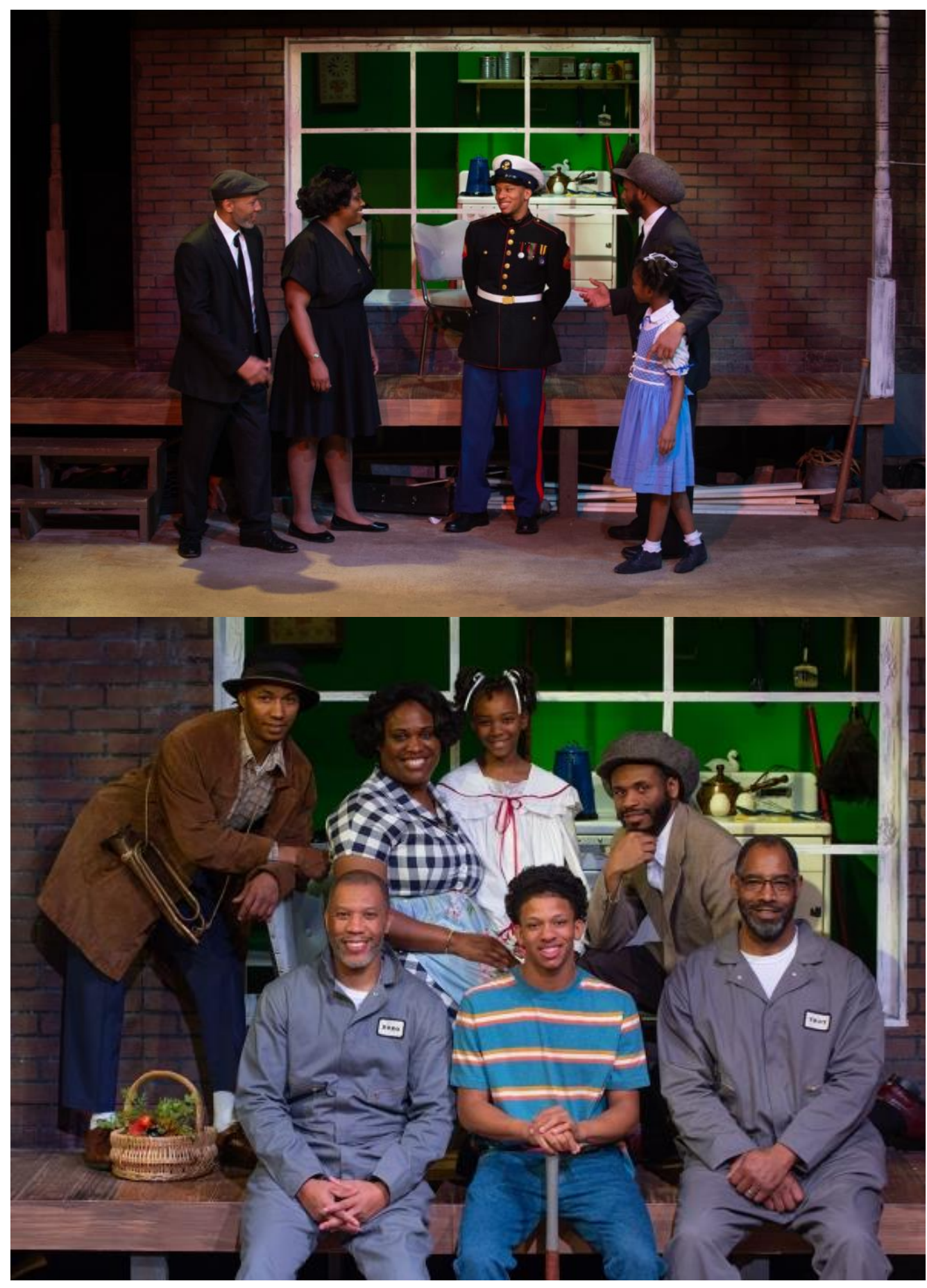

All images courtesy Chattanooga Theatre Centre.

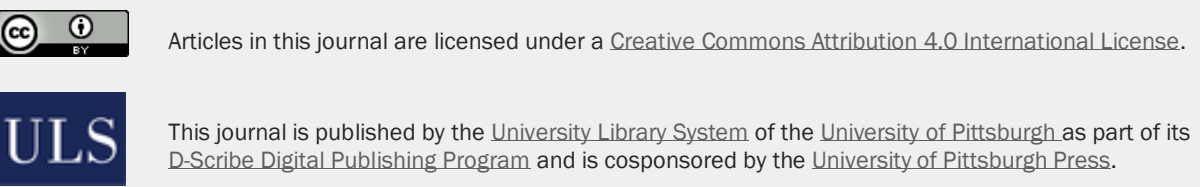

